\title{
Comparative effectiveness of dopamine agonists and monoamine oxidase type-B inhibitors for Parkinson's disease: a multiple treatment comparison meta-analysis
}

\author{
Caroline D. Binde ${ }^{1} \cdot$ Ingunn F. Tvete ${ }^{2} \cdot$ Jørund I. Gåsemyr $^{3} \cdot$ Bent Natvig $^{3} \cdot$ Marianne Klemp $^{1}$ (D)
}

Received: 13 December 2019 / Accepted: 15 July 2020 / Published online: 24 July 2020

(C) The Author(s) 2020

\begin{abstract}
Purpose To investigate the comparative effectiveness of dopamine agonists and monoamine oxidase type-B (MAO-B) inhibitors available for treatment of Parkinson's disease.

Methods We performed a systematic literature search identifying randomized controlled trials investigating 4 dopamine agonists (cabergoline, pramipexole, ropinirole, rotigotine) and 3 MAO-B inhibitors (selegiline, rasagiline, safinamide) for Parkinson's disease. We extracted and pooled data from included clinical trials in a joint model allowing both direct and indirect comparison of the seven drugs. We considered dopamine agonists and MAO-B inhibitors given as monotherapy or in combination with levodopa. Selected endpoints were change in the Unified Parkinson's Disease Rating Scale (UPDRS) score, serious adverse events and withdrawals. We estimated the relative effectiveness of each dopamine agonist and MAO-B inhibitor versus comparator drug.

Results Altogether, 79 publications were included in the analysis. We found all the investigated drugs to be effective compared with placebo when given as monotherapy except safinamide. When considering combination treatment, the estimated relative effects of selegiline, pramipexole, ropinirole, rotigotine, cabergoline, rasagiline and safinamide were 2.316 (1.819, 2.951), 2.091 (1.889, 2.317), 2.037 (1.804, 2.294), 1.912 (1.716, 2.129), 1.664 (1.113, 2.418), 1.584 (1.379, 1.820) and 1.179 (1.031, 1.352), respectively, compared with joint placebo and levodopa treatment.

Conclusions Dopamine agonists were found to be effective as treatment for Parkinson's disease, both when given as monotherapy and in combination with levodopa. Selegiline and rasagiline were also found to be effective for treating Parkinson's disease, and selegiline was the best option in combination with levodopa among all the drugs investigated.
\end{abstract}

Keywords Dopamine agonists $\cdot$ MAO-B inhibitors $\cdot$ Multiple treatment comparison $\cdot$ Parkinson's disease $\cdot$ Effectiveness $\cdot$ Serious adverse events

\section{Introduction}

Pharmacological treatment of Parkinson's disease is complex, as there are several treatment options available, but little

Electronic supplementary material The online version of this article (https://doi.org/10.1007/s00228-020-02961-6) contains supplementary material, which is available to authorized users.

Marianne Klemp

marianne.klemp@medisin.uio.no

Department of Pharmacology, University of Oslo, Oslo, Norway

2 Norwegian Computing Centre, Oslo, Norway

3 Department of Mathematics, University of Oslo, Oslo, Norway information on how these options compare. The main therapeutic strategy for Parkinson's disease has been replacement of dopamine, via the dopamine precursor levodopa $[1,2]$. However, chronic treatment with levodopa is complicated by the development of motor fluctuations, wearing-off effect and random switches between "on" and "off" states [2]. Up to $40 \%$ of patients treated with levodopa for 5 years or more will experience end-of-dose deterioration [3].

There are several agents available for the treatment of Parkinson's disease, and both dopamine agonists and monoamine-oxidase type B (MAO-B) inhibitors can be used alone or in combination with each other or with levodopa. When starting treatment, it is in the best interest of the patient to identify the most effective and safe option from a range of alternatives, as well as to consider whether it is most important 
to obtain control over motor symptoms or to delay development of levodopa side effects. For younger patients, it would be desirable if an alternative treatment option to levodopa could delay the need for levodopa and hence the side effects associated with chronic levodopa treatment. Both dopamine agonists and MAO-B inhibitors are available as alternatives to levodopa, but there is no clear evidence that one of these options is better than the other. Therefore, the comparative effectiveness of dopamine agonists and MAO-B inhibitors, both when given alone and in combination with levodopa, needs to be better established.

We have previously investigated the comparative effectiveness of MAO-B inhibitors available for treatment of Parkinson's disease [4]. We conducted a multiple treatment comparison (MTC) meta-analysis assessing which drug had the highest probability of being the most effective drug for early and late Parkinson's disease. We evaluated both clinical improvement and serious adverse events (SAE). We found that all of the included MAO-B inhibitors (selegiline, rasagiline and safinamide) were effective compared to placebo, both when given alone and in combination with levodopa. When considering combination therapy with MAO-B inhibitors and levodopa, we found that selegiline was the most effective drug [4].

Other reviews have previously compared several drugs used for treatment of Parkinson's disease, but we could not identify any studies performing a comprehensive comparison with dopamine agonists and MAO-B inhibitors available for treatment of Parkinson's disease, both when used as monotherapy and in addition to levodopa. We did a systematic MEDLINE search for systematic reviews and meta-analyses comparing pharmacological treatment for Parkinson's disease, and we found only a few publications. One Cochrane review investigated three drug classes assessing the benefits and risks of these drugs when used in the treatment of patients suffering from Parkinson's disease with motor complications [5]. This review compared catechol-O-methyl transferase (COMT) inhibitors, MAO-B inhibitors and dopamine agonists with placebo when used in combination with levodopa. They found that treatment with dopamine agonists may be more effective than treatment with MAO-B inhibitors and COMT inhibitors in managing symptoms of Parkinson's disease, but regarding dopamine agonists and MAO-B inhibitors, they found no significant differences between individual drugs within each drug class [5].

$\mathrm{Li}$ et al. conducted a network meta-analysis comparing ten drugs used in the treatment of non-motor symptoms of Parkinson's disease [6]. They included trials involving drugs from different drug classes (ropinirole, rasagiline, rotigotine, entacapone, apomorphine, pramipexole, sumarinole, bromocriptine, piribedil and levodopa). They found that among the drugs included in their analysis, apomorphine appeared to be the most efficacious [6].
Zhuo et al. did a comprehensive comparison of ten drugs used in the treatment of Parkinson's disease [7]. Their study was designed to investigate efficacy and tolerability of ten drugs used as monotherapy in the treatment of Parkinson's disease. They found that levodopa, selegiline, ropinirole and rotigotine showed effectiveness and could be recommended as treatment for patients with Parkinson's disease [7]. We think it is important to also investigate the comparative effectiveness of these agents when given in combination with levodopa, and we have therefore included studies examining this. Levodopa is almost unavoidably added to the treatment of Parkinson's disease after a few years, to keep control of the progressive symptoms $[2,8]$.

We therefore extended our previous research [4] to investigate the comparative effectiveness of both dopamine agonists and MAO-B inhibitors available for treatment of Parkinson's disease. We performed a comprehensive literature search and pooled data from all relevant published clinical trials involving four dopamine agonists (cabergoline, pramipexole, rotigotine and ropinirole). We also included published clinical trials considering MAO-B inhibitors from our previous publication [4], allowing both direct and indirect comparisons of all seven drugs in a joint model. There is no single clinical trial actively comparing all dopamine agonists and MAO-B inhibitors, but we can pool data from published clinical trials in an MTC analysis simultaneously to assess which drug has the highest probability of being the most effective or the safest option, both when given alone and in combination with levodopa. Additionally, disease duration, dose level and duration of study could influence the effect and SAE of the various treatments and the degree of withdrawal from the study. We explored this in our analysis.

\section{Methods}

\section{Literature search}

We performed a systematic literature search, using MEDLINE, PubMed and Cochrane Central Register of Controlled Trials, to identify randomized controlled trials (RCTs) assessing the efficacy of dopamine agonists in patients with Parkinson's disease. We included dopamine agonists (cabergoline, pramipexole, apomorphine, ropinirole and rotigotine) and indication (Parkinson's disease) as search terms and limited our search to RCTs (Appendix S1). Two researchers screened the list of potentially eligible clinical trials by title and/or abstract. We retrieved potentially eligible publications for full-text review to determine whether they met our pre-specified inclusion criteria. Publications that included men and women with Parkinson's disease aged 18 years or older, comparing the interventions of interest (cabergoline, pramipexole, ropinirole or rotigotine) with each 
other or placebo, with or without additional levodopa, were eligible. We found the clinical trials assessing the effectiveness of apomorphine to differ too much in administration form (infusion, injection, inhalation and sublingual administration). We therefore decided to exclude studies on apomorphine from the analysis. We searched through reference lists to identify additional trials. The search was conducted on 28 September 2017. We also included 25 publications from our previous review assessing the efficacy of MAO-B inhibitors [4]. Both searches were last updated in May 2019. Details of the identification and selection of publications are displayed in the PRISMA flowchart (Fig. 1).

\section{Participants and study selection}

Two researchers independently reviewed the full-text publications and extracted data from the publications that met our prespecified inclusion criteria. We included publications presenting RCTs of patients with Parkinson's disease above the age of 18 , evaluating the efficacy or safety of dopamine agonists (cabergoline, pramipexole, ropinirole or rotigotine) or MAO$\mathrm{B}$ inhibitors (selegiline, rasagiline or safinamide), given either as monotherapy or in combination with levodopa. According to our study protocol (Appendix S2) which was defined a priori, we extracted data on outcomes of interest, which were change in Unified Parkinson's Disease Rating Scale (UPDRS) [9] score (responders), serious adverse events, withdrawals (discontinuation of drug use), mortality and need for levodopa. There were very few deaths, and we did not have resources to investigate the need for levodopa in depth. Therefore, we present the results regarding the number of responders, serious adverse events and withdrawals in this paper. Publications were excluded if they failed to meet our inclusion criteria regarding trial design, patient population, intervention, comparator or endpoints. Risk of bias of included studies is assessed at study level using the risk of bias tool described in Cochrane Handbook for Systematic Reviews of Interventions and is available in the supplementary materials
Fig. 1 Identification and selection of publications. MAO-B inhibitors included and adapted from [4]

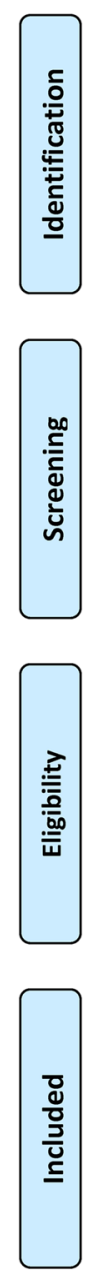

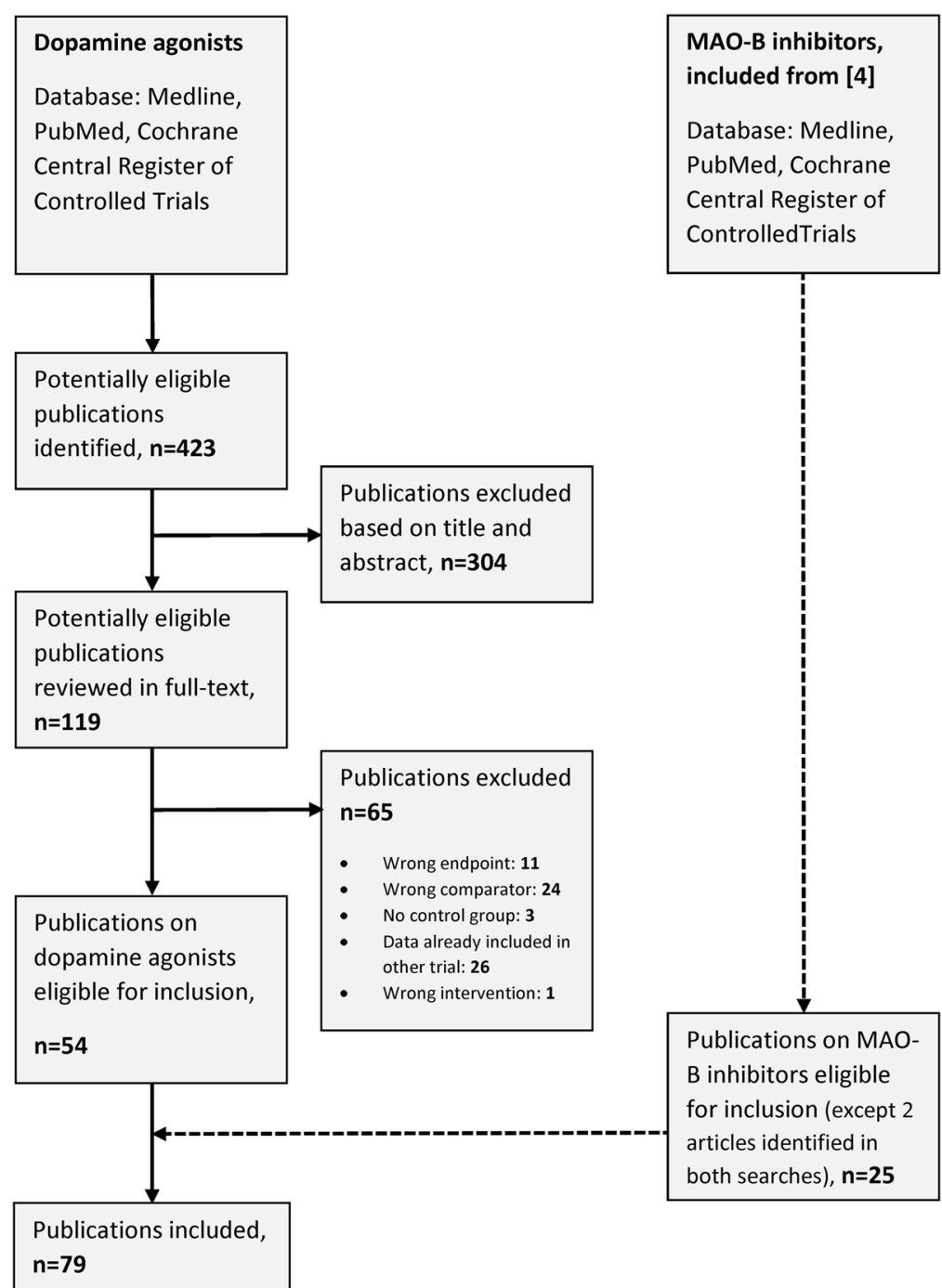


(Appendix S3). The Cochrane risk-of-bias tool for randomized trials (RoB2) [10] was used to assess the risk of bias across five domains: the randomization process, assignment to intervention, missing outcome data, measurement of the outcome and selection of the reported result. Studies showing high risk of bias in two or more domains were excluded from the analysis.

Responders were defined as the number of patients with an improvement (minimally improved, much improved or very much improved) on the Clinical Global Impressions (CGI) scale [11] or with at least $20 \%$ reduction in the UPDRS score from baseline to end of study. The UPDRS total score was used where it was provided; the activities of daily living (ADL) sub-score (part II) and/or the motor sub-score (part III) were used where only these were provided. Entacapone, a catechol-O-methyltransferase (COMT) inhibitor, was used in combination with levodopa as a comparator in one of the included clinical trials, and was therefore indirectly included in the analysis, but was not a drug we focused on.

\section{Data}

We originally found two studies comparing levodopa and ropinirole to levodopa, giving one complete network embracing all treatments from the 79 studies. However, when considering this network, we ran into inconsistency issues. We therefore decided to analyse two separate networks, one considering monotherapy treatments with placebo as the comparator treatment and another considering combination treatment with dopamine agonists or MAO-B inhibitors and levodopa with placebo and levodopa treatment as the comparator treatment. We will refer to these two networks as, respectively, networks 1 and 2 (Fig. 2).
We defined disease duration as short (less than 3 years) or long (3 years or more). Dose level was defined as low or high with individual cut-off levels for the different Parkinson drugs (Appendix S4). Duration of study was defined as short (less than 26 weeks) or long (26 weeks or more).

\section{Statistical analysis}

For both networks, we constructed a joint model for assessing the comparable relative effects, the relative risk of withdrawal and the relative risk of serious adverse events between the treatments for each treatment versus the relevant comparator, following Tvete et al. [12]. The relevant comparators were placebo and joint placebo and levodopa treatment in the first and second network, respectively. All treatment arms over all studies in a network contributed to the comparison of all drugs relative to each other. We give a detailed presentation of the model in the supplementary material (Appendix S5).

In our Bayesian modelling approach, we estimated, taking into consideration the study data, the posterior distribution of the relative effect of one drug versus another. We addressed the possible presence of heterogeneity by adjusting for known relevant factors as suggested in Higgins et al. 2003 [13]. We hence considered models where we related the treatments' effect to the disease duration, dose level and study duration, giving a regression coefficient in each case to be estimated.

We analysed the models in OpenBUGS [14] run from $R$ [15]. In network 1, we sampled from the posterior distribution of the relative effect of each drug versus each other and versus placebo. In network 2, we sampled for the posterior distribution of the relative effect of each drug in combined treatment with levodopa versus each other in combined treatment with
Fig. 2 Overview of direct and indirect comparisons. The numbers and the thickness of the lines indicate the number of clinical trials in each comparison

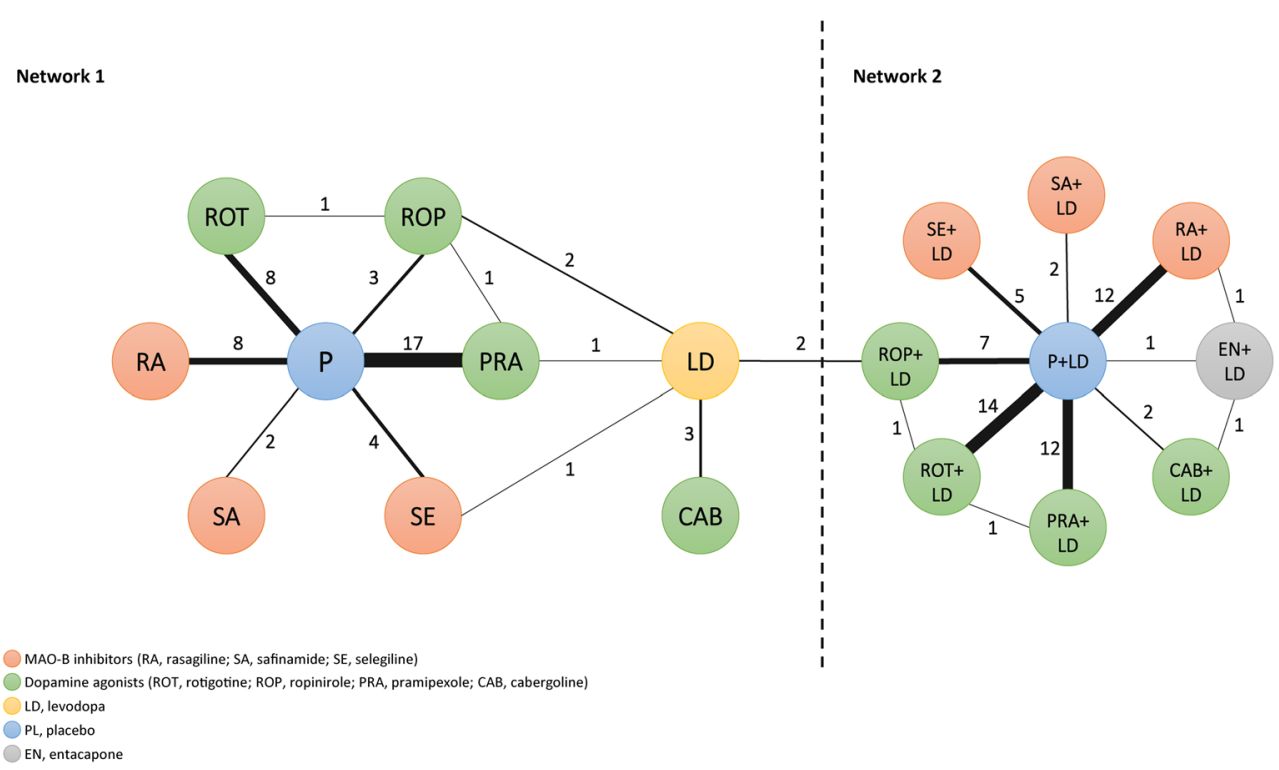


levodopa and versus joint placebo and levodopa treatment. Similarly, in models adjusting for either dose level, duration of disease or duration of study, we sampled from the posterior distribution of the respective regression coefficients. Based on the posterior samples, we estimated all parameters entering the model, including the relative effects. A visual inspection of the MCMC chains and computing Rhat [16], the potential scale reduction factor, for the parameters entering the models were done to check for convergence issues.

We present all estimates with corresponding 95\% uncertainty (credibility) intervals. Based on the posterior samples, we could estimate the probability that one treatment was better than another by counting the number of times; the corresponding relative effect was greater. Similarly, we could estimate the probability that a treatment was ranked as number 1 and 2 .

\section{Results}

We identified 423 potentially eligible publications assessing the efficacy of dopamine agonists, where 304 were excluded based on title and abstract. One hundred and nineteen publications were retrieved for full-text review. Of these, 65 were found to be not relevant and were excluded (Appendix S6). Fifty-four publications on dopamine agonists and 25 publications on MAO-B inhibitors from our previous review [4] were included. Altogether, 79 publications were included in the multiple treatment comparison analysis (Appendix S7) [17-95].

The 79 publications included a total of 20,773 patients, of which 8381 received treatment with a dopamine agonist (given as monotherapy or in combination with levodopa) and 3736 received a MAO-B inhibitor (given as monotherapy or in combination with levodopa). A total of 3386 patients received placebo and 4077 received placebo and levodopa. Eight hundred and eighty-four patients received levodopa only, and 309 patients received entacapone. The average disease duration ranged from 3 months to almost 14 years. A total of 9036 patients had disease duration of less than 3 years, and 11,737 patients had disease duration of 3 years or more. The durations of the clinical trials ranged from 6 weeks to six and a half years, most of them lasting between 12 and 36 weeks.

The number of responders and serious adverse events extracted from the studies are presented in the supplementary materials (Appendix S8 and S9). Figure 2 displays the two networks of direct and indirect comparisons. Altogether, there are 51 comparisons in network 1 (monotherapy) and 59 in network 2 (combination therapy) (Fig. 2 and Appendix S7). All of the included clinical trials are considered to have low or medium risk of bias (Appendix S3).

\section{Treatment effect}

\section{Network 1}

Analysing network 1 without taking dose level, duration of disease or duration of study into account, we found monotherapy with dopamine agonists (cabergoline, pramipexole, rotigotine and ropinirole), MAO-B inhibitors (selegiline, rasagiline and safinamide) and levodopa, to be effective compared with placebo, except safinamide. We found ropinirole to be the most effective option, followed by levodopa. Next pramipexole, rotigotine, selegiline and rasagiline were of similar effect, followed by cabergoline. The estimated relative effects are 2.171 (1.888, 2.489), 2.017 (1.733, 2.336), 1.774 (1.607, 1.958), 1.745 (1.514, 2.009), 1.697 (1.491, 1.924), $1.657(1.509,1.818)$ and $1.402(1.114,1.732)$ respectively (Table 1). The effect estimate for safinamide was similar to that of cabergoline but was associated with large uncertainty, the credibility interval containing 1 . Figure 3 displays the ranking of the dopamine agonists and the MAO-B inhibitors when given alone. The probability that one drug is better than another is displayed in Table 2 . We found $82 \%$ probability for ropinirole to be better than levodopa and a $99 \%$ probability for ropinirole to be better than pramipexole. Similarly, there is a 93\% probability for levodopa to be better than pramipexole (Table 2).

We found no significant difference in treatment effect for patients with high-dose compared with low-dose level or for patients with short compared with long disease duration, i.e. the coefficients for dose level and disease duration were not significantly different from zero. However, the coefficient for duration of study was significantly different from 0 . Hence, the model including an effect of study duration was the model best supported by the data.

Taking duration of study into consideration, we found an increased effect with longer duration of study. After adjusting for duration of study, rasagiline receives a better ranking and is ranked as number three together with pramipexole, following ropinirole and levodopa (Table 1). There were short duration of study in 44 treatment arms and long duration of study in 41 treatment arms.

\section{Network 2}

Regarding treatment with a dopamine agonist or a MAO-B inhibitor in combination with levodopa, we found all of the included drugs to be effective compared with placebo. We found selegiline to be the most effective option, followed by pramipexole and ropinirole, rotigotine, cabergoline and rasagiline, and safinamide. The estimated relative effects are 2.316 (1.819, 2.951), 2.091 (1.889, 2.317), 2.037 (1.804, 2.294), 1.912 (1.716, 2.129), 1.664 (1.113, 2.418), 1.584 $(1.379,1.820)$ and $1.179(1.031,1.352)$ respectively 
Table 1 UPDRS responders, serious adverse events and withdrawals in the networks; effect ratio estimates

\begin{tabular}{|c|c|c|c|c|c|c|c|c|c|}
\hline & & \multicolumn{3}{|c|}{ MAO-B inhibitors } & \multicolumn{4}{|c|}{ Dopamine agonists } & \multirow{2}{*}{$\begin{array}{l}\text { Other } \\
\text { LD }\end{array}$} \\
\hline & & RA & SA & SE & $\mathrm{CAB}$ & PRA & ROP & ROT & \\
\hline \multirow[t]{5}{*}{$\begin{array}{c}\text { Network } \\
1\end{array}$} & $\begin{array}{l}\text { UPDRS } \\
\text { responders }^{\mathrm{a}}\end{array}$ & $\begin{array}{c}1.657(1.509 \\
1.818)\end{array}$ & $\begin{array}{c}1.468(0.888 \\
2.393)\end{array}$ & $\begin{array}{c}1.697(1.491, \\
1.924)\end{array}$ & $\begin{array}{c}1.402(1.114 \\
1.732)\end{array}$ & $\begin{array}{c}1.774(1.607 \\
1.958)\end{array}$ & $\begin{array}{l}2.171(1.888 \\
2.489)\end{array}$ & $\begin{array}{c}1.745(1.514 \\
2.009)\end{array}$ & $\begin{array}{c}2.017(1.733 \\
2.336)\end{array}$ \\
\hline & $\begin{array}{l}\text { UPDRS } \\
\text { responders }\end{array}$ & $\begin{array}{c}1.797(1.675 \\
1.926)\end{array}$ & $\begin{array}{c}1.361(0.836 \\
2.074)\end{array}$ & $\begin{array}{c}1.663(1.463, \\
1.884)\end{array}$ & $\begin{array}{c}1.329(1.063 \\
1.642)\end{array}$ & $\begin{array}{c}1.763(1.614 \\
1.919)\end{array}$ & $\begin{array}{c}1.953(1.647 \\
2.266)\end{array}$ & $\begin{array}{c}1.552(1.373 \\
1.749)\end{array}$ & $\begin{array}{c}1.915(1.638 \\
2.232)\end{array}$ \\
\hline & $\begin{array}{c}\text { Serious } \\
\text { adverse } \\
\text { events }\end{array}$ & $\begin{array}{c}1.048(0.613 \\
1.709)\end{array}$ & $\begin{array}{l}1.054(0.325 \\
2.461)\end{array}$ & $\begin{array}{c}0.789(0.285 \\
1.714)\end{array}$ & $\begin{array}{c}1.026(0.567 \\
1.664)\end{array}$ & $\begin{array}{l}2.021(1.394 \\
2.885)\end{array}$ & $\begin{array}{c}1.163(0.765 \\
1.645)\end{array}$ & $\begin{array}{c}0.900(0.624 \\
1.245)\end{array}$ & $\begin{array}{c}0.833(0.482 \\
1.313)\end{array}$ \\
\hline & Withdrawals & $\begin{array}{c}0.865(0.648 \\
1.089)\end{array}$ & $\begin{array}{c}0.954(0.601 \\
1.361)\end{array}$ & $\begin{array}{c}1.175(0.86 \\
1.592)\end{array}$ & $\begin{array}{c}0.985(0.765 \\
1.229)\end{array}$ & $\begin{array}{c}1.104(0.926 \\
1.283)\end{array}$ & $\begin{array}{c}0.848(0.728 \\
0.979)\end{array}$ & $\begin{array}{c}1.091(0.922 \\
1.293)\end{array}$ & $\begin{array}{c}0.785(0.628 \\
0.951)\end{array}$ \\
\hline & & $\mathrm{RA}+\mathrm{LD}$ & $\mathrm{SA}+\mathrm{LD}$ & $\mathrm{SE}+\mathrm{LD}$ & $\mathrm{CAB}+\mathrm{LD}$ & $\mathrm{PRA}+\mathrm{LD}$ & $\mathrm{ROP}+\mathrm{LD}$ & $\mathrm{ROT}+\mathrm{LD}$ & $\mathrm{EN}+\mathrm{LD}$ \\
\hline \multirow[t]{4}{*}{$\begin{array}{l}\text { Network } \\
2\end{array}$} & $\begin{array}{l}\text { UPDRS } \\
\text { responders }^{\mathrm{a}}\end{array}$ & $\begin{array}{c}1.584(1.379 \\
1.82)\end{array}$ & $\begin{array}{c}1.179(1.031 \\
1.352)\end{array}$ & $\begin{array}{c}2.316(1.819 \\
2.951)\end{array}$ & $\begin{array}{c}1.664(1.113 \\
2.418)\end{array}$ & $\begin{array}{c}2.091(1.889 \\
2.317)\end{array}$ & $\begin{array}{c}2.037(1.804 \\
2.294)\end{array}$ & $\begin{array}{c}1.912(1.716 \\
2.129)\end{array}$ & $\begin{array}{c}1.429(1.16 \\
1.74)\end{array}$ \\
\hline & $\begin{array}{l}\text { UPDRS } \\
\text { responders }\end{array}$ & $\begin{array}{c}1.544(1.349 \\
1.762)\end{array}$ & $\begin{array}{c}1.217(1.066 \\
1.392)\end{array}$ & $\begin{array}{c}2.503(1.946, \\
3.222)\end{array}$ & $\begin{array}{c}1.455(1.006 \\
2.068)\end{array}$ & $\begin{array}{c}2.093(1.891 \\
2.316)\end{array}$ & $\begin{array}{c}2.095(1.861 \\
2.356)\end{array}$ & $\begin{array}{c}1.933(1.737 \\
2.149)\end{array}$ & $\begin{array}{c}1.312(1.098 \\
1.570)\end{array}$ \\
\hline & $\begin{array}{l}\text { Serious } \\
\text { adverse } \\
\text { events }\end{array}$ & $\begin{array}{c}1.052(0.812 \\
1.405)\end{array}$ & $\begin{array}{c}1.043(0.837 \\
1.343)\end{array}$ & $\begin{array}{c}1.045(0.818, \\
1.394)\end{array}$ & $\begin{array}{c}0.969(0.652 \\
1.281)\end{array}$ & $\begin{array}{c}1.034(0.806 \\
1.337)\end{array}$ & $\begin{array}{c}1.012(0.799 \\
1.278)\end{array}$ & $\begin{array}{c}1.030(0.791 \\
1.352)\end{array}$ & $\begin{array}{c}1.006(0.755 \\
1.323)\end{array}$ \\
\hline & Withdrawals & $\begin{array}{c}0.903(0.690 \\
1.201)\end{array}$ & $\begin{array}{c}1.113(0.782 \\
1.571)\end{array}$ & $\begin{array}{c}0.955(0.774 \\
1.159)\end{array}$ & $\begin{array}{c}0.854(0.522 \\
1.334)\end{array}$ & $\begin{array}{l}0.616(0.524 \\
0.72)\end{array}$ & $\begin{array}{c}0.615(0.526 \\
0.713)\end{array}$ & $\begin{array}{c}0.809(0.690 \\
0.945)\end{array}$ & $\begin{array}{c}0.957(0.654 \\
1.34)\end{array}$ \\
\hline
\end{tabular}

${ }^{a}$ Model without taking dose level, duration of disease or duration of study into consideration

${ }^{\mathrm{b}}$ Model taking duration of study into consideration

$R A$, rasagiline; $S A$, safinamide; $S E$, selegiline; $C A B$, cabergoline; $P R A$, pramipexole; $R O P$, ropinirole; $R O T$, rotigotine; $L D$, levodopa; $E N$, entacapone
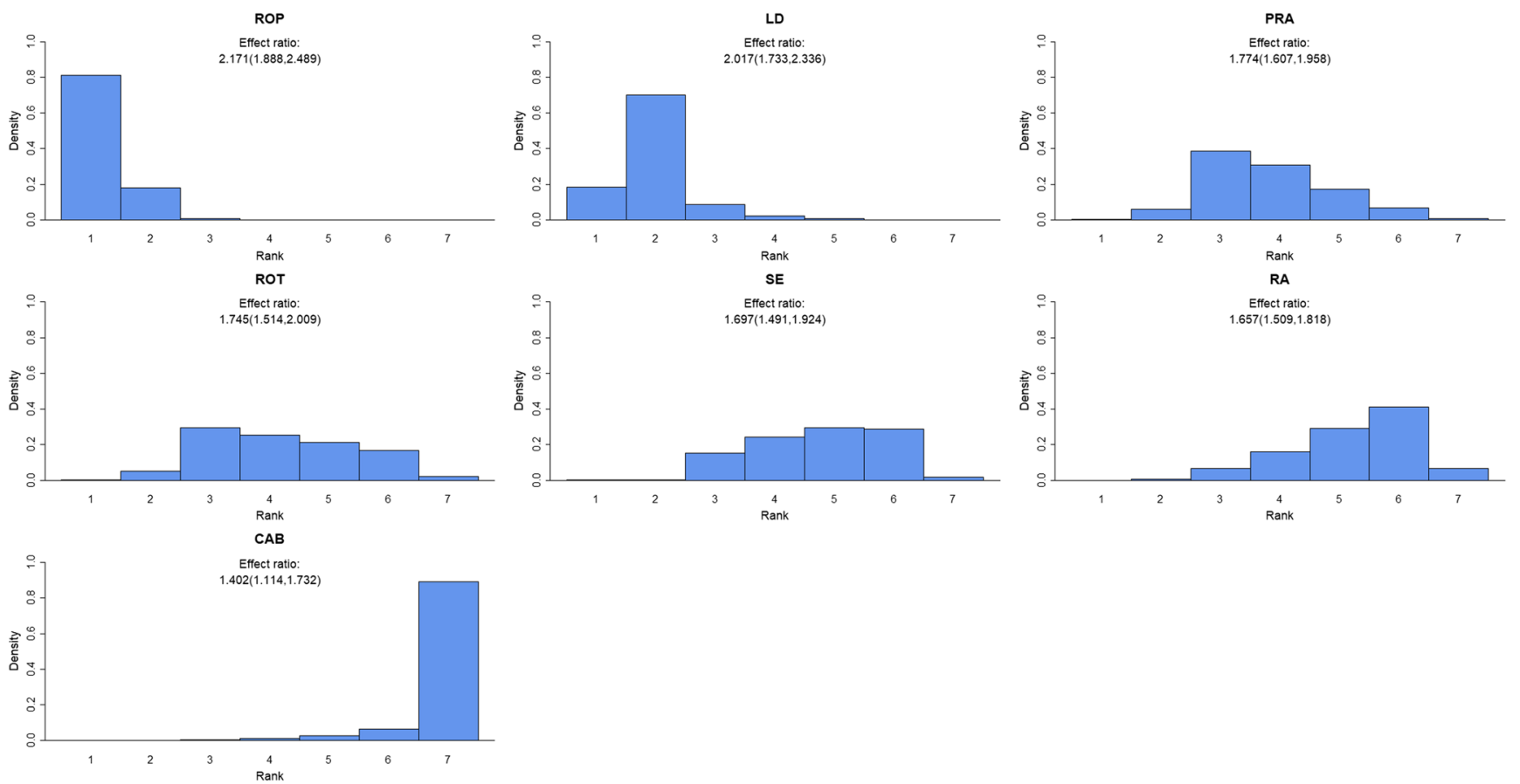

estimated effect of given drug versus placebo treatment. ROP, ropinirole;

Fig. 3 Histograms displaying a given dopamine agonist or MAO-B inhibitor's effect ranked against the other drugs (ranked from left to right) when given as monotherapy. The height of the bars gives the probability of being ranked as number one to seven. The effect ratios are the

LD, levodopa; PRA, pramipexole; ROT, rotigotine; SE, selegiline; RA, rasagiline; $\mathrm{CAB}$, cabergoline 
Table 2 Probabilities that one drug is better than another regarding responders, in a model without dose level, duration of disease or duration of study Probability that one drug is better than another given alone

\begin{tabular}{|c|c|c|c|c|c|c|c|}
\hline & LD & PRA & ROT & $\mathrm{SE}$ & RA & $\mathrm{CAB}$ & SA \\
\hline ROP & 0.82 & 0.99 & 1 & 1 & 1 & 1 & 0.94 \\
\hline LD & - & 0.93 & 0.94 & 1 & 0.99 & 1 & 0.90 \\
\hline PRA & - & - & 0.58 & 0.72 & 0.84 & 0.98 & 0.81 \\
\hline ROT & - & - & - & 0.63 & 0.72 & 0.96 & 0.79 \\
\hline SE & - & - & - & - & 0.61 & 0.97 & 0.76 \\
\hline RA & - & - & - & - & - & 0.92 & 0.73 \\
\hline $\mathrm{CAB}$ & - & - & - & - & - & - & 0.48 \\
\hline \multicolumn{8}{|c|}{ Probability that one drug is better than another in combination with levodopa } \\
\hline & $\mathrm{PRA}+\mathrm{LD}$ & $\mathrm{ROP}+\mathrm{LD}$ & ROT + LD & $\mathrm{CAB}+\mathrm{LD}$ & $\mathrm{RA}+\mathrm{LD}$ & $\mathrm{EN}+\mathrm{LD}$ & $\mathrm{SA}+\mathrm{LD}$ \\
\hline $\mathrm{SE}+\mathrm{LD}$ & 0.76 & 0.81 & 0.92 & 0.93 & 1 & 1 & 1 \\
\hline $\mathrm{PRA}+\mathrm{LD}$ & - & 0.64 & 0.94 & 0.89 & 1 & 1 & 1 \\
\hline $\mathrm{ROP}+\mathrm{LD}$ & - & - & 0.83 & 0.86 & 1 & 1 & 1 \\
\hline $\mathrm{ROT}+\mathrm{LD}$ & - & - & - & 0.78 & 0.98 & 0.99 & 1 \\
\hline $\mathrm{CAB}+\mathrm{LD}$ & - & - & - & - & 0.56 & 0.76 & 0.94 \\
\hline $\mathrm{RA}+\mathrm{LD}$ & - & - & - & - & - & 0.87 & 1 \\
\hline $\mathrm{EN}+\mathrm{LD}$ & - & - & - & - & - & - & 0.94 \\
\hline
\end{tabular}

$R A$, rasagiline; $S A$, safinamide; $S E$, selegiline; $C A B$, cabergoline; $P R A$, pramipexole; $R O P$, ropinirole; $R O T$, rotigotine; $L D$, levodopa; $E N$, entacapone

(Table 1). The ranking of the drugs when given in combination with levodopa is displayed in Fig. 4. Table 2 displays the probability that one agent is better than another. We found a
$76 \%$ probability for selegiline to be better than pramipexole and $81 \%$ probability for selegiline to be better than ropinirole when given as combination therapy. Similarly, we find a $64 \%$
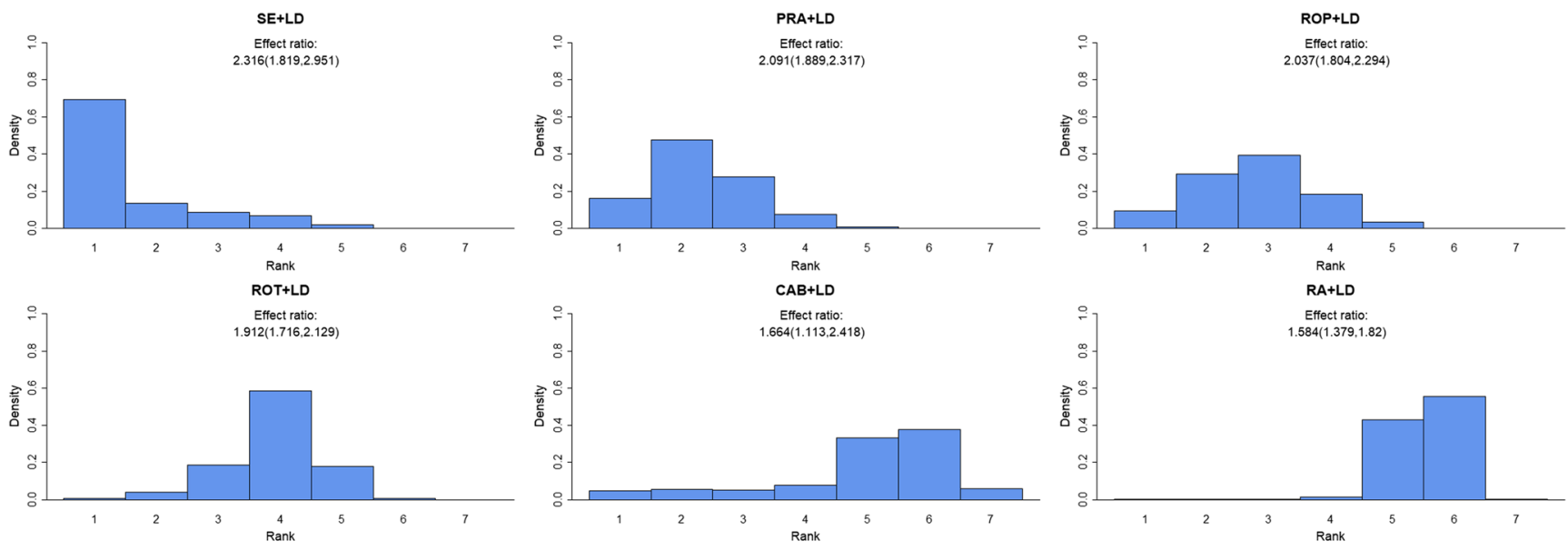

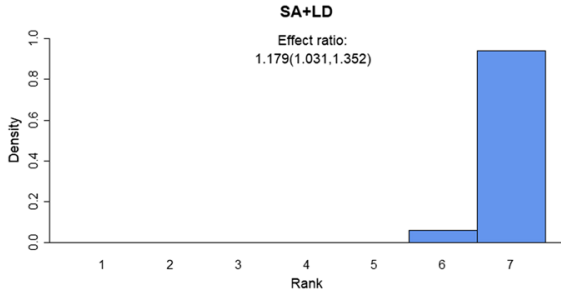

Fig. 4 Histograms displaying given dopamine agonist or MAO-B inhibitor's effect ranked against the other drugs (ranked from left to right) when given in combination with levodopa. The height of the bars gives the probability of being ranked as number one to seven. The effect rations are the estimated effect of the given drug versus placebo treatment when given in combination with levodopa. SE, selegiline; PRA, pramipexole; ROP, ropinirole; ROT, rotigotine; $\mathrm{CAB}$, cabergoline; $\mathrm{RA}$, rasagiline; $\mathrm{SA}$, safinamide 
probability for pramipexole to be better than ropinirole when given together with levodopa (Table 2).

Taking the dose level or disease duration into consideration, we found an increased effect with a high-dose level compared with a low-dose level and similarly an increased effect for those with long disease duration compared with having short disease duration. For both cases, the ranking of the drugs did not change. Considering duration of the study, the coefficient for study duration was close to but just above zero (lower level in the uncertainty interval was less than 0.00003 ). The ranking of the drugs is the same as without considering study duration, with the exception that rasagiline and cabergoline switched rank, with the estimated relative effects $1.544(1.349,1.762)$ and $1.455(1.006,2.068)$, respectively (Table 1). Hence, rasagiline and cabergoline remain similar in effect when taking study duration into account.

\section{Serious adverse events}

In network 1, we find an increased risk of serious adverse events for treatment with pramipexole compared with placebo (Table 1). For network 2, we find no increased risk of serious adverse events for any of the drugs compared with placebo (Table 1). There were altogether few serious adverse events, and we did not consider patients' dose level, disease duration or the study duration for the serious adverse event endpoint.

\section{Withdrawals}

Considering withdrawals in network 1 , we found no increased risk of withdrawals for any of the drugs compared with placebo. However, we find a significantly lower risk of withdrawals for treatment with ropinirole and levodopa compared with placebo, $0.848(0.728,0.979)$ and $0.785(0.628,0.951)$, respectively (Table 1). In network 2 (combination therapy), we find no increased risk of withdrawals for any of the drugs compared with placebo, but we found a significantly lower risk of withdrawals for treatment with pramipexole, ropinirole and rotigotine, $0.616(0.524,0.720), 0.615(0.526,0.713)$ and $0.809(0.690,0.945)$, respectively (Table 1$)$. There were altogether relatively few withdrawals, and we did not consider patients' dose level, disease duration or the study duration for the withdrawal endpoint.

\section{Discussion}

There is a variety of medical interventions available for the symptomatic treatment of Parkinson's disease, but there is little information on how these options compare. We aimed to do a comprehensive comparison of dopamine agonists and MAO-B inhibitors available for treatment of Parkinson's disease, both when given alone and in combination with levodopa.

We included 79 clinical trials including a total of 20,773 patients. Our results suggest that both dopamine agonists and MAO-B inhibitors are effective as monotherapy treatment for patients with Parkinson's disease. We found the dopamine agonist ropinirole to be the best treatment. Noticeably, we found ropinirole to be ranked higher than levodopa when given as monotherapy. However, we did not actively search for clinical trials comparing levodopa with placebo, so we cannot exclude the possibility that we are lacking evidence on this part. We found a considerable variation in treatment effect within each drug class, especially within the class of dopamine agonists.

When considering combination treatment for Parkinson's disease, we found selegiline to be the most effective drug in combination with levodopa. These results are in line with the results of our previous publication, where we investigated the efficacy and safety of three MAO-B inhibitors (selegiline, rasagiline, and safinamide) and found selegiline to be the most effective option when given in combination with levodopa [4]. Interestingly, selegiline remains the most effective drug in combination with levodopa after adding all the evidence connected to four dopamine agonists to the analysis. Also for combination treatment, we found considerable variation within each drug class, especially for MAO-B inhibitors. Except for selegiline, no other MAO-B inhibitor was ranked higher than a dopamine agonist when used in combination with levodopa.

It has previously been reported that MAO-B inhibitors appear to have weaker anti-Parkinsonian effect than levodopa $[96,97]$ and dopamine agonists [97]. Our results support these findings only to some extent. Regarding monotherapy, we found that MAO-B inhibitors appear less effective than the dopamine agonist ropinirole and levodopa. We found selegiline and rasagiline to be the best of the three MAO-B inhibitors included in the analysis for monotherapy. However, it has also been reported a beneficial association between the duration of treatment with MAO-B inhibitors and the degree of clinical worsening [98]. The durations of the clinical trials in our analysis ranged from 6 weeks to six and a half years, most of them lasting between 12 and 36 weeks. When adjusting for duration of study, we found in general an increased effect with longer duration of study. Interestingly, after adjusting for the duration of study, rasagiline received a better ranking and was ranked as number three following ropinirole and levodopa.

Dopamine agonists are associated with more side effects $[97,99]$, and we found an increased risk of serious adverse events for patients treated with pramipexole. However, we found no increased risk of withdrawals from any of the drugs used as monotherapy compared with placebo. In fact, we found a significantly lower risk of withdrawal for treatment 
with ropinirole and levodopa, compared with placebo. Regarding combination therapy, we found no increased risk of withdrawals compared with placebo. On the contrary, we found a reduced risk of withdrawals in the groups treated with pramipexole, ropinirole and rotigotine in combination with levodopa, compared with placebo in combination with levodopa. This could suggest that patients tolerate the treatment well, even though there might be side effects, or that the experience of improved health effects outweighs the experience of possible side effects.

Comparisons of different treatment options for Parkinson's disease have previously been reported, although we could not identify any review comparing all dopamine agonists and MAO-B inhibitors available for treatment of Parkinson's disease, both when used as monotherapy and in combination with levodopa. Zhuo et al. [7] recommend, in a comprehensive comparison, levodopa, selegiline, ropinirole and rotigotine for monotherapy in patients with Parkinson's disease, and these results are in line with our results.

Patients with Parkinson's disease are affected differently, and the need for pharmacological therapy varies for different ages and stages of the disease. As the treatment strategies are considered individually for each patient with Parkinson's disease, it is reassuring for both clinicians and patients that the results from this MTC analysis indicate that all of the included dopamine agonists and MAO-B inhibitors, except safinamide, are effective compared with placebo. We found dopamine agonists, in particular ropinirole and pramipexole, to be effective and safe as monotherapy in managing symptoms of Parkinson's disease. Although we found an increased risk of side effects related to pramipexole, we also found that there was no increased risk of withdrawal with this treatment, suggesting that the benefits from this treatment might outweigh the potential harms. Considering combination therapy, we found selegiline, ropinirole and pramipexole to be both effective and safe treatment options for these patients.

There are some limitations to this study. As with any MTC analysis, there is a potential weakness regarding the comparability of the included trials. Differences in patient demographics and the follow-up time might potentially introduce heterogeneity in the results. We adjusted for dose level, disease duration and duration of study, which will capture some of the possible differences, but other variables could also have been considered. However, considering too many variables could potentially lead to exclusion of too many trials due to lack of information, which again could introduce selection bias. Secondly, it is known that studies with positive findings are more likely to be published than studies with negative findings, giving a biased MTC analysis. We only had access to published studies, and that should be kept in mind when considering the results. With respect to our focus of ranking the drugs, we have no reason to believe that the publication bias was greater for some drugs than others.
In conclusion, we found dopamine agonists to be effective as treatment for Parkinson's disease, both when given as monotherapy and in combination with levodopa, and the MAO-B inhibitor selegiline was found to be the best option when given in combination with levodopa. Treatment options must be individualized and tailored to the needs of each individual patient.

Acknowledgements Open Access funding provided by University of Oslo (incl Oslo University Hospital).

Authors' Contributions CDB carried out the clinical part and made a first draft of the manuscript. IFT performed the statistical analyses and drafted the manuscript. JG participated in the statistical part and commented on the manuscript. BN participated in the statistical part and commented on the manuscript. MK was responsible for the project and participated in its planning, implementation and drafting of the manuscript.

Data availability statement The data that supports the findings in this study are available in the supplementary material of this article (Appendix S8 and S9). The complete dataset is available from the researchers upon request.

\section{Compliance with ethical standards}

Conflict of interest The authors declare that they have no conflict of interests.

Open Access This article is licensed under a Creative Commons Attribution 4.0 International License, which permits use, sharing, adaptation, distribution and reproduction in any medium or format, as long as you give appropriate credit to the original author(s) and the source, provide a link to the Creative Commons licence, and indicate if changes were made. The images or other third party material in this article are included in the article's Creative Commons licence, unless indicated otherwise in a credit line to the material. If material is not included in the article's Creative Commons licence and your intended use is not permitted by statutory regulation or exceeds the permitted use, you will need to obtain permission directly from the copyright holder. To view a copy of this licence, visit http://creativecommons.org/licenses/by/4.0/.

\section{References}

1. Obeso JA, Olanow CW, Nutt JG (2000) Levodopa motor complications in Parkinson's disease. Trends Neurosci 23(10 Suppl):S2S7

2. Rascol O, Lozano A, Stern M, Poewe W (2011) Milestones in Parkinson's disease therapeutics. Mov Disord 26(6):1072-1082. https://doi.org/10.1002/mds.23714

3. Marsden CD, Parkes JD (1977) Success and problems of longterm levodopa therapy in Parkinson's disease. Lancet 1(8007): 345-349

4. Binde CD, Tvete IF, Gasemyr J, Natvig B, Klemp M (2018) A multiple treatment comparison meta-analysis of monoamine oxidase type B inhibitors for Parkinson's disease. Br J Clin Pharmacol 84(9):1917-1927. https://doi.org/10.1111/bcp.13651

5. Stowe R, Ives N, Clarke CE, Deane K, Van H, Wheatley K, Gray R, Handley K, Furmston A (2010) Evaluation of the efficacy and safety of adjuvant treatment to levodopa therapy in Parkinson s 
disease patients with motor complications. Cochrane Database Syst Rev (7):CD007166. https://doi.org/10.1002/14651858. CD007166.pub2

6. Li BD, Cui JJ, Song J, Qi C, Ma PF, Wang YR, Bai J (2018) Comparison of the efficacy of different drugs on non-motor symptoms of Parkinson's disease: a network meta-analysis. Cell Physiol Biochem 45(1):119-130. https://doi.org/10.1159/ 000486252

7. Zhuo C, Zhu X, Jiang R, Ji F, Su Z, Xue R, Zhou Y (2017) Comparison for efficacy and tolerability among ten drugs for treatment of Parkinson's disease: a network meta-analysis. Sci Rep 8: 45865. https://doi.org/10.1038/srep45865

8. Goetz CG, Pal G (2014) Initial management of Parkinson's disease. BMJ 349:g6258. https://doi.org/10.1136/bmj.g6258

9. Fahn S, Elton R, Committee MotUD (1987) Unified Parkinson's disease rating scale. Recent Developments in Parkinson's Disease. 2(153-163):293-304

10. Sterne JAC, Savović J, Page MJ, Elbers RG, Blencowe NS, Boutron I, Cates CJ, Cheng HY, Corbett MS, Eldridge SM, Emberson JR, Hernán MA, Hopewell S, Hróbjartsson A, Junqueira DR, Jüni P, Kirkham JJ, Lasserson T, Li T, McAleenan A, Reeves BC, Shepperd S, Shrier I, Stewart LA, Tilling K, White IR, Whiting PF, Higgins JPT (2019) RoB 2: a revised tool for assessing risk of bias in randomised trials. BMJ 366:14898. https://doi.org/10.1136/bmj.14898

11. Guy W (1976) Clinical global Imression (CGI). ECDEU assessment manual for psychopharmacology Rockville, MD, U.S. Department of Health, education, and welfare

12. Tvete IF, Natvig B, Gasemyr J, Meland N, Roine M, Klemp M (2015) Comparing effects of biologic agents in treating patients with rheumatoid arthritis: a multiple treatment comparison regression analysis. PLoS One 10(9):e0137258. https://doi.org/10.1371/ journal.pone. 0137258

13. Higgins JPT, Thompson SG, Deeks JJ, Altman DG (2003) Measuring inconsistency in meta-analyses. BMJ 327(7414): 557-560. https://doi.org/10.1136/bmj.327.7414.557

14. Lunn DJ, Thomas A, Best N, Spiegelhalter D (2000) WinBUGS a Bayesian modelling framework: concepts, structure, and extensibility. Stat Comput 10(4):325-337. https://doi.org/10.1023/a: 1008929526011

15. R Core Team A language and environment for statistical computing. R Foundation for Statistical Computing. http://www.Rproject.org/

16. Gelman A, Rubin DB (1992) Inference from iterative simulation using multiple sequences. Stat Sci 7(4):457-472. https://doi.org/ $10.1214 / \mathrm{ss} / 1177011136$

17. Steiger MJ, El-Debas T, Anderson T, Findley LJ, Marsden CD (1996) Double-blind study of the activity and tolerability of cabergoline versus placebo in parkinsonians with motor fluctuations. J Neurol 243(1):68-72

18. Utsumi $\mathrm{H}$, Cabergoline as the starting $\mathrm{T}$, its long-term effects study G (2012) Long-term effects of cabergoline and levodopa in Japanese patients with early Parkinson's disease: a 5-year prospective study. Acta Medica Okayama 66(2):163-170. https://doi. org/10.18926/AMO/48266

19. Storch A, Wolz M, Beuthien-Baumann B, Lohle M, Herting B, Schwanebeck U, Oehme L, van den Hoff J, Perick M, Grahlert X, Kotzerke J, Reichmann H (2013) Effects of dopaminergic treatment on striatal dopamine turnover in de novo Parkinson disease. Neurology 80(19):1754-1761. https://doi.org/10.1212/WNL. 0b013e3182918c2d

20. Deuschl G, Vaitkus A, Fox GC, Roscher T, Schremmer D, Gordin A, Group CS (2007) Efficacy and tolerability of entacapone versus cabergoline in parkinsonian patients suffering from wearing-off. Mov Disord 22(11):1550-1555. https://doi.org/10.1002/mds. 21473
21. Hutton JT, Koller WC, Ahlskog JE, Pahwa R, Hurtig HI, Stern MB, Hiner BC, Lieberman A, Pfeiffer RF, Rodnitzky RL, Waters CH, Muenter MD, Adler CH, Morris JL (1996) Multicenter, placebo-controlled trial of cabergoline taken once daily in the treatment of Parkinson's disease. Neurology 46(4):1062-1065

22. Bracco F, Battaglia A, Chouza C, Dupont E, Gershanik O, Marti Masso JF, Montastruc JL, Group PS (2004) The long-acting dopamine receptor agonist cabergoline in early Parkinson's disease: final results of a 5-year, double-blind, levodopa-controlled study. [erratum appears in CNS drugs. 2005;19(7):633]. CNS Drugs 18(11):733-746

23. Barone P, Poewe W, Albrecht S, Debieuvre C, Massey D, Rascol O, Tolosa E, Weintraub D (2010) Pramipexole for the treatment of depressive symptoms in patients with Parkinson's disease: a randomised, double-blind, placebo-controlled trial. Lancet Neurol 9(6):573-580. https://doi.org/10.1016/S1474-4422(10) 70106-X

24. Group PS (1997) Safety and efficacy of pramipexole in early Parkinson disease. A randomized dose-ranging study. Parkinson Study Group. JAMA 278(2):125-130

25. Molho ES, Factor SA, Weiner WJ, Sanchez-Ramos JR, Singer C, Shulman L, Brown D, Sheldon C (1995) The use of pramipexole, a novel dopamine (DA) agonist, in advanced Parkinson's disease. J Neural Transm Suppl 45:225-230

26. Parkinson Study G (2007) Pramipexole in levodopa-treated Parkinson disease patients of African, Asian, and Hispanic heritage. Clin Neuropharmacol 30(2):72-85. https://doi.org/10.1097/ 01.wnf.0000240943.59617.4c

27. Pinter MM, Pogarell O, Oertel WH (1999) Efficacy, safety, and tolerance of the non-ergoline dopamine agonist pramipexole in the treatment of advanced Parkinson's disease: a double blind, placebo controlled, randomised, multicentre study. J Neurol Neurosurg Psychiatry 66(4):436-441

28. Pogarell O, Gasser T, van Hilten JJ, Spieker S, Pollentier S, Meier D, Oertel WH (2002) Pramipexole in patients with Parkinson's disease and marked drug resistant tremor: a randomised, double blind, placebo controlled multicentre study. J Neurol Neurosurg Psychiatry 72(6):713-720

29. Shannon KM, Bennett JP Jr, Friedman JH (1997) Efficacy of pramipexole, a novel dopamine agonist, as monotherapy in mild to moderate Parkinson's disease. The Pramipexole Study Group. [Erratum appears in Neurology 1998 Mar;50(3):838]. Neurology 49(3):724-728

30. Wermuth L (1998) A double-blind, placebo-controlled, randomized, multi-center study of pramipexole in advanced Parkinson's disease. Eur J Neurol 5(3):235-242

31. Wong KS, Lu CS, Shan DE, Yang CC, Tsoi TH, Mok V (2003) Efficacy, safety, and tolerability of pramipexole in untreated and levodopa-treated patients with Parkinson's disease. J Neurol Sci 216(1):81-87

32. Schapira AH, McDermott MP, Barone P, Comella CL, Albrecht S, Hsu HH, Massey DH, Mizuno Y, Poewe W, Rascol O, Marek K (2013) Pramipexole in patients with early Parkinson's disease (PROUD): a randomised delayed-start trial. Lancet Neurol 12(8): 747-755. https://doi.org/10.1016/S1474-4422(13)70117-0

33. Moller JC, Oertel WH, Koster J, Pezzoli G, Provinciali L (2005) Long-term efficacy and safety of pramipexole in advanced Parkinson's disease: results from a European multicenter trial. Mov Disord 20(5):602-610. https://doi.org/10.1002/mds.20397

34. Hauser RA, Schapira AH, Rascol O, Barone P, Mizuno Y, Salin L, Haaksma M, Juhel N, Poewe W (2010) Randomized, doubleblind, multicenter evaluation of pramipexole extended release once daily in early Parkinson's disease. Mov Disord 25(15): 2542-2549. https://doi.org/10.1002/mds.23317

35. Schapira AH, Barone P, Hauser RA, Mizuno Y, Rascol O, Busse M, Salin L, Juhel N, Poewe W, Pramipexole ERSG (2011) 
Extended-release pramipexole in advanced Parkinson disease: a randomized controlled trial. Neurology 77(8):767-774. https:// doi.org/10.1212/WNL.0b013e31822affdb

36. Mizuno Y, Yanagisawa N, Kuno S, Yamamoto M, Hasegawa K, Origasa H, Kowa H, Japanese pramipexole study G (2003) Randomized, double-blind study of pramipexole with placebo and bromocriptine in advanced Parkinson's disease. Mov Disord 18(10):1149-1156. https://doi.org/10.1002/mds.10508

37. Hubble JP, Koller WC, Cutler NR, Sramek JJ, Friedman J, Goetz C, Ranhosky A, Korts D, Elvin A (1995) Pramipexole in patients with early Parkinson's disease. Clin Neuropharmacol 18(4):338 347

38. Parkinson Study G, Holloway RG, Shoulson I, Fahn S, Kieburtz K, Lang A, Marek K, McDermott M, Seibyl J, Weiner W, Musch B, Kamp C, Welsh M, Shinaman A, Pahwa R, Barclay L, Hubble J, LeWitt P, Miyasaki J, Suchowersky O, Stacy M, Russell DS, Ford B, Hammerstad J, Riley D, Standaert D, Wooten F, Factor S, Jankovic J, Atassi F, Kurlan R, Panisset M, Rajput A, Rodnitzky R, Shults C, Petsinger G, Waters C, Pfeiffer R, Biglan K, Borchert L, Montgomery A, Sutherland L, Weeks C, DeAngelis M, Sime E, Wood S, Pantella C, Harrigan M, Fussell B, Dillon S, AlexanderBrown B, Rainey P, Tennis M, Rost-Ruffner E, Brown D, Evans S, Berry D, Hall J, Shirley T, Dobson J, Fontaine D, Pfeiffer B, Brocht A, Bennett S, Daigneault S, Hodgeman K, O'Connell C, Ross T, Richard K, Watts A (2004) Pramipexole vs levodopa as initial treatment for Parkinson disease: a 4-year randomized controlled trial. [Erratum appears in Arch Neurol. 2005 Mar;62(3): 430]. Arch Neurol 61(7):1044-1053. https://doi.org/10.1001/ archneur.61.7.1044

39. Parkinson Study Group Prami BIDI (2011) Twice-daily, low-dose pramipexole in early Parkinson's disease: a randomized, placebocontrolled trial. Mov Disord 26(1):37-44. https://doi.org/10.1002/ mds. 23396

40. Sampaio C, Bronzova J, Hauser RA, Lang AE, Rascol O, van de Witte SV, Theeuwes AA, Rembrandt/Vermeer Study G (2011) Pardoprunox in early parkinson's disease: results from 2 large, randomized double-blind trials. Mov Disord 26(8):1464-1476. https://doi.org/10.1002/mds. 23590

41. Lieberman A, Ranhosky A, Korts D (1997) Clinical evaluation of pramipexole in advanced Parkinson's disease: results of a doubleblind, placebo-controlled, parallel-group study. Neurology 49(1): $162-168$

42. Guttman M (1997) Double-blind comparison of pramipexole and bromocriptine treatment with placebo in advanced Parkinson's disease. International Pramipexole-Bromocriptine Study Group. Neurology 49(4):1060-1065

43. Poewe W, Rascol O, Barone P, Hauser RA, Mizuno Y, Haaksma M, Salin L, Juhel N, Schapira AH, Pramipexole ERSG (2011) Extended-release pramipexole in early Parkinson disease: a 33week randomized controlled trial. Neurology 77(8):759-766. https://doi.org/10.1212/WNL.0b013e31822affb0

44. Zhang Z, Wang J, Zhang X, Chen S, Wang Z, Zhang B, Liu C, Qu Q, Cheng Y, Li J, Cao H, Cai M, Zhu R (2013) The efficacy and safety of ropinirole prolonged release tablets as adjunctive therapy in Chinese subjects with advanced Parkinson's disease: a multicenter, double-blind, randomized, placebo-controlled study. [Erratum appears in Parkinsonism Relat Disord. 2014 Aug;20(8):943-4]. Parkinsonism Relat Disord 19(11):1022 1026. https://doi.org/10.1016/j.parkreldis.2013.07.009

45. Watts RL, Lyons KE, Pahwa R, Sethi K, Stern M, Hauser RA, Olanow W, Gray AM, Adams B, Earl NL, Study I (2010) Onset of dyskinesia with adjunct ropinirole prolonged-release or additional levodopa in early Parkinson's disease. Mov Disord 25(7):858 866. https://doi.org/10.1002/mds. 22890

46. Whone AL, Watts RL, Stoessl AJ, Davis M, Reske S, Nahmias C, Lang AE, Rascol O, Ribeiro MJ, Remy P, Poewe WH, Hauser
RA, Brooks DJ, Group R-PS (2003) Slower progression of Parkinson's disease with ropinirole versus levodopa: the REALPET study. Ann Neurol 54(1):93-101. https://doi.org/10.1002/ ana.10609

47. Rascol O, Lees AJ, Senard JM, Pirtosek Z, Montastruc JL, Fuell D (1996) Ropinirole in the treatment of levodopa-induced motor fluctuations in patients with Parkinson's disease. Clin Neuropharmacol 19(3):234-245

48. Brooks DJ, Abbott RJ, Lees AJ, Martignoni E, Philcox DV, Rascol O, Roos RA, Sagar HJ (1998) A placebo-controlled evaluation of ropinirole, a novel D2 agonist, as sole dopaminergic therapy in Parkinson's disease. Clin Neuropharmacol 21(2):101107

49. Singer C, Lamb J, Ellis A, Layton G, Sumanirole for early Parkinson's disease study G (2007) A comparison of sumanirole versus placebo or ropinirole for the treatment of patients with early Parkinson's disease. Mov Disord 22(4):476-482. https://doi.org/ 10.1002/mds. 21361

50. Lieberman A, Olanow CW, Sethi K, Swanson P, Waters CH, Fahn S, Hurtig H, Yahr M (1998) A multicenter trial of ropinirole as adjunct treatment for Parkinson's disease. Ropinirole Study Group. [Erratum appears in Neurology 1999 Jan 15;52(2):435]. Neurology 51(4):1057-1062

51. Rakshi JS, Pavese N, Uema T, Ito K, Morrish PK, Bailey DL, Brooks DJ (2002) A comparison of the progression of early Parkinson's disease in patients started on ropinirole or L-dopa: an 18F-dopa PET study. J Neural Transm 109(12):1433-1443. https://doi.org/10.1007/s00702-002-0753-0

52. Pahwa R, Stacy MA, Factor SA, Lyons KE, Stocchi F, Hersh BP, Elmer LW, Truong DD, Earl NL, Investigators E-PAS (2007) Ropinirole 24-hour prolonged release: randomized, controlled study in advanced Parkinson disease. Neurology 68(14):1108 1115. https://doi.org/10.1212/01.wnl.0000258660.74391.c1

53. Barone P, Lamb J, Ellis A, Clarke Z (2007) Sumanirole versus placebo or ropinirole for the adjunctive treatment of patients with advanced Parkinson's disease. Mov Disord 22(4):483-489. https://doi.org/10.1002/mds.21191

54. Rascol O, Brooks DJ, Korczyn AD, De Deyn PP, Clarke CE, Lang AE (2000) A five-year study of the incidence of dyskinesia in patients with early Parkinson's disease who were treated with ropinirole or levodopa. N Engl J Med 342(20):1484-1491. https:// doi.org/10.1056/NEJM200005183422004

55. Mizuno Y, Abe T, Hasegawa K, Kuno S, Kondo T, Yamamoto M, Nakashima M, Kanazawa I, Group SS (2007) Ropinirole is effective on motor function when used as an adjunct to levodopa in Parkinson's disease: STRONG study. Mov Disord 22(13):1860 1865. https://doi.org/10.1002/mds.21313

56. Thomas A, Bonanni L, Di Iorio A, Varanese S, Anzellotti F, D'Andreagiovanni A, Stocchi F, Onofrj M (2006) End-of-dose deterioration in non ergolinic dopamine agonist monotherapy of Parkinson's disease. J Neurol 253(12):1633-1639. https://doi.org/ 10.1007/s00415-006-0320-z

57. Mizuno Y, Nomoto M, Hasegawa K, Hattori N, Kondo T, Murata M, Takeuchi M, Takahashi M, Tomida T, Rotigotine Trial G (2014) Rotigotine vs ropinirole in advanced stage Parkinson's disease: a double-blind study. Parkinsonism Relat Disord 20(12):1388-1393. https://doi.org/10.1016/j.parkreldis.2014.10. 005

58. Parkinson Study G (2003) A controlled trial of rotigotine monotherapy in early Parkinson's disease. Arch Neurol 60(12):17211728. https://doi.org/10.1001/archneur.60.12.1721

59. Poewe WH, Rascol O, Quinn N, Tolosa E, Oertel WH, Martignoni E, Rupp M, Boroojerdi B, Investigators SP (2007) Efficacy of pramipexole and transdermal rotigotine in advanced Parkinson's disease: a double-blind, double-dummy, randomised 
controlled trial. Lancet Neurol 6(6):513-520. https://oi.org/10. 1016/s1471-4422(07)70108-4

60. Antonini A, Bauer L, Dohin E, Oertel WH, Rascol O, Reichmann H, Schmid M, Singh P, Tolosa E, Chaudhuri KR (2015) Effects of rotigotine transdermal patch in patients with Parkinson's disease presenting with non-motor symptoms - results of a double-blind, randomized, placebo-controlled trial. Eur J Neurol 22(10):1400 1407. https://doi.org/10.1111/ene.12757

61. Hauser RA, Slawek J, Barone P, Dohin E, Surmann E, Asgharnejad M, Bauer L (2016) Evaluation of rotigotine transdermal patch for the treatment of apathy and motor symptoms in Parkinson's disease. BMC Neurol 16:90. https://doi.org/10.1186/ s12883-016-0610-7

62. Nomoto M, Mizuno Y, Kondo T, Hasegawa K, Murata M, Takeuchi M, Ikeda J, Tomida T, Hattori N (2014) Transdermal rotigotine in advanced Parkinson's disease: a randomized, doubleblind, placebo-controlled trial. J Neurol 261(10):1887-1893. https://doi.org/10.1007/s00415-014-7427-3

63. Rascol O, Zesiewicz T, Chaudhuri KR, Asgharnejad M, Surmann E, Dohin E, Nilius S, Bauer L (2016) A randomized controlled exploratory pilot study to evaluate the effect of rotigotine transdermal patch on Parkinson's disease-associated chronic pain. J Clin Pharmacol 56(7):852-861. https://doi.org/10.1002/jcph.678

64. Trenkwalder C, Kies B, Rudzinska M, Fine J, Nikl J, Honczarenko K, Dioszeghy P, Hill D, Anderson T, Myllyla V, Kassubek J, Steiger M, Zucconi M, Tolosa E, Poewe W, Surmann E, Whitesides J, Boroojerdi B, Chaudhuri KR, Recover Study G (2011) Rotigotine effects on early morning motor function and sleep in Parkinson's disease: a double-blind, randomized, placebo-controlled study (RECOVER). Mov Disord 26(1):90 99. https://doi.org/10.1002/mds.23441

65. Jankovic J, Watts RL, Martin W, Boroojerdi B (2007) Transdermal rotigotine: double-blind, placebo-controlled trial in Parkinson disease. Arch Neurol 64(5):676-682. https://doi.org/ 10.1001/archneur.64.5.676

66. Mizuno $\mathrm{Y}$, Nomoto M, Kondo T, Hasegawa K, Murata M, Takeuchi M, Ikeda J, Tomida T, Hattori N, Rotigotine Trial G (2013) Transdermal rotigotine in early stage Parkinson's disease: a randomized, double-blind, placebo-controlled trial. Mov Disord 28(10):1447-1450. https://doi.org/10.1002/mds.25537

67. Giladi N, Boroojerdi B, Korczyn AD, Burn DJ, Clarke CE, Schapira AH, investigators SP (2007) Rotigotine transdermal patch in early Parkinson's disease: a randomized, double-blind, controlled study versus placebo and ropinirole. Mov Disord 22(16):2398-2404. https://doi.org/10.1002/mds.21741

68. Nicholas AP, Borgohain R, Chana P, Surmann E, Thompson EL, Bauer L, Whitesides J, Elmer LW, Investigators SPS (2014) A randomized study of rotigotine dose response on 'off' time in advanced Parkinson's disease. J Parkinsons Dis Print 4(3):361-373. https://doi.org/10.3233/JPD-130320

69. Chung SJ, Asgharnejad M, Bauer L, Ramirez F, Jeon B (2016) Evaluation of rotigotine transdermal patch for the treatment of depressive symptoms in patients with Parkinson's disease. Expert Opin Pharmacother 17(11):1453-1461. https://doi.org/10. 1080/14656566.2016.1202917

70. Le Witt PA, Lyons KE, Pahwa R, Group SPS (2007) Advanced Parkinson disease treated with rotigotine transdermal system: PREFER Study. Neurology 68(16):1262-1267. https://doi.org/ 10.1212/01.wnl.0000259516.61938.bb

71. Barone P, Santangelo G, Morgante L, Onofrj M, Meco G, Abbruzzese G, Bonuccelli U, Cossu G, Pezzoli G, Stanzione P, Lopiano L, Antonini A, Tinazzi M (2015) A randomized clinical trial to evaluate the effects of rasagiline on depressive symptoms in non-demented Parkinson's disease patients. Eur J Neurol 22(8): 1184-1191. https://doi.org/10.1111/ene.12724
72. Frakey LL, Friedman JH (2017) Cognitive effects of Rasagiline in mild-to-moderate stage Parkinson's disease without dementia. J Neuropsychiatry Clin Neurosci 29(1):22-25. https://doi.org/10. 1176/appi.neuropsych.15050118

73. Hanagasi HA, Gurvit H, Unsalan P, Horozoglu H, Tuncer N, Feyzioglu A, Gunal DI, Yener GG, Cakmur R, Sahin HA, Emre $M$ (2011) The effects of rasagiline on cognitive deficits in Parkinson's disease patients without dementia: a randomized, double-blind, placebo-controlled, multicenter study. Mov Disord 26(10):1851-1858. https://doi.org/10.1002/mds.23738

74. Hauser RA, Stocchi F, Rascol O, Huyck SB, Capece R, Ho TW, Sklar P, Lines C, Michelson D, Hewitt D (2015) Preladenant as an adjunctive therapy with levodopa in Parkinson disease: two randomized clinical trials and lessons learned. JAMA Neurol 72(12): 1491-1500. https://doi.org/10.1001/jamaneurol.2015.2268

75. Lim TT, Kluger BM, Rodriguez RL, Malaty IA, Palacio R Jr, Ojo OO, Patel S, Gujrati Y, Nutter B, Swartz C, Hennessy C, Fernandez HH (2015) Rasagiline for the symptomatic treatment of fatigue in Parkinson's disease. Mov Disord 30(13):1825-1830. https://doi.org/10.1002/mds.26429

76. Olanow CW, Rascol O, Hauser R, Feigin PD, Jankovic J, Lang A, Langston W, Melamed E, Poewe W, Stocchi F, Tolosa E, Investigators AS (2009) A double-blind, delayed-start trial of rasagiline in Parkinson's disease. N Engl J Med 361(13):12681278. https://doi.org/10.1056/NEJMoa0809335

77. Parkinson Study G (2002) A controlled trial of rasagiline in early Parkinson disease: the TEMPO Study. Arch Neurol 59(12):19371943

78. Parkinson Study G (2005) A randomized placebo-controlled trial of rasagiline in levodopa-treated patients with Parkinson disease and motor fluctuations: the PRESTO study. Arch Neurol 62(2): 241-248. https://doi.org/10.1001/archneur.62.2.241

79. Rabey JM, Sagi I, Huberman M, Melamed E, Korczyn A, Giladi N, Inzelberg R, Djaldetti R, Klein C, Berecz G, Rasagiline Study G (2000) Rasagiline mesylate, a new MAO-B inhibitor for the treatment of Parkinson's disease: a double-blind study as adjunctive therapy to levodopa. Clin Neuropharmacol 23(6):324-330

80. Rascol O, Brooks DJ, Melamed E, Oertel W, Poewe W, Stocchi F, Tolosa E, group Ls (2005) Rasagiline as an adjunct to levodopa in patients with Parkinson's disease and motor fluctuations (LARGO, lasting effect in adjunct therapy with rasagiline given once daily, study): a randomised, double-blind, parallel-group trial. Lancet 365(9463):947-954. https://doi.org/10.1016/S01406736(05)71083-7

81. Stern MB, Marek KL, Friedman J, Hauser RA, LeWitt PA, Tarsy D, Olanow CW (2004) Double-blind, randomized, controlled trial of rasagiline as monotherapy in early Parkinson's disease patients. Mov Disord 19(8):916-923. https://doi.org/10.1002/mds.20145

82. Stocchi F, Rascol O, Hauser RA, Huyck S, Tzontcheva A, Capece R, Ho TW, Sklar P, Lines C, Michelson D, Hewitt DJ, Preladenant Early Parkinson Disease Study G (2017) Randomized trial of preladenant, given as monotherapy, in patients with early Parkinson disease. Neurology 88(23):2198-2206. https://doi.org/ 10.1212/WNL.0000000000004003

83. Zhang L, Zhang Z, Chen Y, Qin X, Zhou H, Zhang C, Sun H, Tang R, Zheng J, Yi L, Deng L, Li J (2013) Efficacy and safety of rasagiline as an adjunct to levodopa treatment in Chinese patients with Parkinson's disease: a randomized, double-blind, parallelcontrolled, multi-centre trial. Int J Neuropsychopharmacol 16(7): 1529-1537. https://doi.org/10.1017/S1461145713000175

84. Borgohain R, Szasz J, Stanzione P, Meshram C, Bhatt MH, Chirilineau D, Stocchi F, Lucini V, Giuliani R, Forrest E, Rice P, Anand R, Study I (2014) Two-year, randomized, controlled study of safinamide as add-on to levodopa in mid to late Parkinson's disease. Mov Disord 29(10):1273-1280. https://doi. org/10.1002/mds.25961 
85. Stocchi F, Arnold G, Onofrj M, Kwiecinski H, Szczudlik A, Thomas A, Bonuccelli U, Van Dijk A, Cattaneo C, Sala P, Fariello RG, Safinamide Parkinson's Study G (2004) Improvement of motor function in early Parkinson disease by safinamide. Neurology 63(4):746-748

86. Allain H, Pollak P, Neukirch HC (1993) Symptomatic effect of selegiline in de novo Parkinsonian patients. The French Selegiline Multicenter Trial. Mov Disord 8(Suppl 1):S36-S40

87. Caraceni T, Musicco M (2001) Levodopa or dopamine agonists, or deprenyl as initial treatment for Parkinson's disease. A randomized multicenter study. Parkinsonism Relat Disord 7(2):107-114

88. Larsen JP, Boas J, Erdal JE (1999) Does selegiline modify the progression of early Parkinson's disease? Results from a fiveyear study. The Norwegian-Danish Study Group. Eur J Neurol 6(5):539-547

89. Mally J, Kovacs AB, Stone TW (1995) Delayed development of symptomatic improvement by (-)-deprenyl in Parkinson's disease. J Neurol Sci 134(1-2):143-145

90. Olanow CW, Hauser RA, Gauger L, Malapira T, Koller W, Hubble J, Bushenbark K, Lilienfeld D, Esterlitz J (1995) The effect of deprenyl and levodopa on the progression of Parkinson's disease. Ann Neurol 38(5):771-777. https://doi.org/ 10.1002/ana.410380512

91. Palhagen S, Heinonen E, Hagglund J, Kaugesaar T, Maki-Ikola O, Palm R, Swedish Parkinson Study G (2006) Selegiline slows the progression of the symptoms of Parkinson disease. Neurology 66(8):1200-1206. https://doi.org/10.1212/01.wnl.0000204007. 46190.54

92. Parkinson Study G (1989) Effect of deprenyl on the progression of disability in early Parkinson's disease. N Engl J Med 321(20): 1364-1371. https://doi.org/10.1056/NEJM198911163212004

93. Shoulson I, Oakes D, Fahn S, Lang A, Langston JW, Le Witt P, Olanow CW, Penney JB, Tanner C, Kieburtz K, Rudolph A, Parkinson Study G (2002) Impact of sustained deprenyl (selegiline) in levodopa-treated Parkinson's disease: a randomized placebo-controlled extension of the deprenyl and tocopherol antioxidative therapy of parkinsonism trial. Ann Neurol 51(5): 604-612. https://doi.org/10.1002/ana.10191

94. Takahashi M, Yuasa R, Imai T, Tachibana H, Yorifuji S, Nakamura Y, Ogawa N (1994) Selegiline (L-deprenyl) and Ldopa treatment of Parkinson's disease: a double-blind trial. Intern Med 33(9):517-524

95. Tetrud JW, Langston JW (1989) The effect of deprenyl (selegiline) on the natural history of Parkinson's disease. Science 245(4917):519-522

96. Robakis D, Fahn S (2015) Defining the role of the monoamine oxidase-B inhibitors for Parkinson's disease. CNS Drugs 29(6): 433-441. https://doi.org/10.1007/s40263-015-0249-8

97. Fox SH, Katzenschlager R, Lim SY, Barton B, de Bie RMA, Seppi K, Coelho M, Sampaio C, Movement Disorder Society Evidence-Based Medicine C (2018) International Parkinson and movement disorder society evidence-based medicine review: update on treatments for the motor symptoms of Parkinson's disease. Mov Disord 33:1248-1266. https://doi.org/10.1002/mds.27372

98. Hauser RA, Li R, Perez A, Ren X, Weintraub D, Elm J, Goudreau JL, Morgan JC, Fang JY, Aminoff MJ, Christine CW, Dhall R, Umeh CC, Boyd JT, Stover N, Leehey M, Zweig RM, Nicholas AP, Bodis-Wollner I, Willis A, Kieburtz K, Tilley BC, Investigators NN-P (2017) Longer duration of MAO-B inhibitor exposure is associated with less clinical decline in Parkinson's disease: an analysis of NET-PD LS1. J Park Dis 7(1):117-127. https://doi.org/10.3233/JPD-160965

99. Stowe RL, Ives NJ, Clarke C, van Hilten J, Ferreira J, Hawker RJ, Shah L, Wheatley K, Gray R (2008) Dopamine agonist therapy in early Parkinson's disease. Cochrane Database Syst Rev (2): CD006564. https://doi.org/10.1002/14651858.CD006564.pub2

100. Higgins JPT TJ, Chandler J, Cumpston M, Li T, Page MJ, Welch VA (editors) (2019) Cochrane Handbook for Systematic Reviews of Interventions version 6.0

Publisher's note Springer Nature remains neutral with regard to jurisdictional claims in published maps and institutional affiliations. 